\title{
Analysis of NOAA particle data and correlations to seismic activity
}

\author{
C. Fidani ${ }^{1}$ and R. Battiston ${ }^{1,2}$ \\ ${ }^{1}$ INFN, Via A. Pascoli, Perugia, Italy \\ ${ }^{2}$ Dipartimento di Fisica Università di Perugia, Via A. Pascoli, Perugia, Italy
}

Received: 14 July 2008 - Revised: 26 September 2008 - Accepted: 29 September 2008 - Published: 26 November 2008

\begin{abstract}
A decade of NOAA-15 particle flux data offers an opportunity to test claims of correlations between seismic activity and effects on the ionosphere. Over the last two decades, potentially interesting observations in the ionosphere-magnetosphere transition region have been investigated. Specifically these consists of anomalous particle fluxes detected by several space experiments and correlated with the earthquake occurrence. These particle fluxes are characterised by anomalous short-term and sharp increases in high energy particle counting rates, referred to as particle bursts. In this work, more general rules for particle bursts selection have been defined and tested on the NOAA database, for particles inside and outside the South Atlantic Anomaly region. The whole period of ten years burst activity from NOAA-15 database is reported. Data from four satellites, NOAA-15, 16, 17 and 18, were analyzed during periods of solar quiet activity in connection with strong earthquakes, revealing presence of bursts detected on more than one satellite close to the time of the same seismic events. This preliminary study presented here concentrates on periods of major Indonesian earthquakes from 1998 to date, including Sumatra event $M=9$, during which geomagnetic Ap index was less than 16 and with no sudden ionospheric disturbances. During this period particle burst temporal distributions have shown some correspondence with earthquake times. The limits of the analysis presented in this papers are discussed as well as prospects for future work.
\end{abstract}

\section{Introduction}

This study presents for the first time some preliminary result of an ongoing analysis of the National Oceanic and Atmospheric Administration (NOAA) particle database in connec-

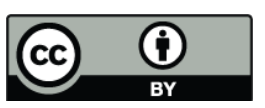

Correspondence to: C. Fidani (cristiano.fidani@ fisica.unipg.it) tion with seismic activity. This work started in 2006 from a general study of particle data (Esposito, 2008).

The NOAA and the National Aeronautics and Space Administration (NASA) jointly developed a series of Polar Operational Environmental Satellites (POES). These Advanced TIROSN (ATN) spacecrafts, named after the prototype satellites, TIROS-N (Television Infrared Observation Satellites), have been flying since 1978 (Davis, 2007). The system consists of pairs of satellites, which ensure that every part of the Earth is regularly observed at least twice every $12 \mathrm{~h}$ from about $800 \mathrm{~km}$ altitude. Starting with the NOAA-15 satellite in 1998, an upgraded version of the Space Environment Monitor (SEM-2) is being flown. The SEM-2 contains two sets of instruments that monitor the energetic chargedparticle environment near the Earth. They detect and monitor the influx of energetic ions and electrons into the atmosphere and the particle radiation environment at the altitude of the satellite.

Geomagnetic and ionospheric activities need to be taken into account because of their relevant influences on fluxes recorded from NOAA particle telescopes. Particle fluxes vary principally as a result of geomagnetic storms of which solar origin depends on the temporal response of magnetosphere plasma to the solar wind speed (Baker, 2000). Links between electron fluxes recorded by NOAA satellites and solar activity were studied in connection with geomagnetic storms (Obara et al., 2001), under the radiation belts (Grigoryan et al., 2008) and in the inner belts within the South Atlantic Anomaly (SAA) (Asikainen and Mursula, 2008). Similar studies have been carried out on NOAA proton fluxes in connection with geomagnetic storms (Soraas et al., 1999), under the radiation belts (Soraas et al., 2002) and within them (Evans et al., 2008). These studies show the influence on the data of solar wind speed; moreover, the ionosphere is influenced by electromagnetic emissions coming from solar flares. Sudden Ionospheric Disturbances (SID) are caused by $\mathrm{X}$-Ray and ultraviolet ionisation followed by particle precipitation (Huang et al., 2007). SID are also produced by Gamma

Published by Copernicus Publications on behalf of the European Geosciences Union. 
Ray Bursts as the X-Ray portion of these events will have the same effect as a solar flares X-Ray emissions (Mandea and Balasis, 2006).

Several types of electromagnetic waves in the ionosphere and magnetosphere can produce particle acceleration and precipitation (Millan and Thorne, 2007). A brief list of such phenomena include: electron precipitation coincident with ELF/VLF wave bursts (Walt et al., 2002); ULF modulation of energetic particles in the dayside magnetosphere (Zong et al., 2007); electron micro-bursts in association with chorus (Lorentzen, 2001); acceleration and loss depending on plasmaspheric hiss (Meredith et al., 2004); precipitation of radiation belt electrons induced by whistlers (Lauben et al., 2001); electron precipitation induced by magnetospheric reflected whistler waves (Bortnik et al., 2006); pitch-angle scattering by electromagnetic ion cyclotron waves (Summers and Thorne, 2003). Some mechanical wave interactions were investigated: acceleration by fast magnetosonic waves (Horne et al., 2007) and electrons precipitation in relation to equatorial plasma wave turbulence phenomena (Morioka et al., 2001). Furthermore, there are some kinds of electromagnetic waves coming from the surface of the earth, such as anthropogenic noise and natural emissions. In order to explain the existence of electron precipitation zones at middle latitudes, several hypotheses are currently under investigation (Millan and Thorne, 2007). One of these hypotheses regarding the connection with ground-based radio-transmitters has been recently confirmed (Inan et al., 2007a). Another hypothesis concerning global thunderstorms activity has also been considered and it was confirmed that lightning induces electron precipitation (Inan et al., 2007b).

Short term variations in high energy charged particles fluxes near the South Atlantic Anomaly (SAA) space were associated to seismic activity (Voronov et al., 1989). The electromagnetic link between particle fluxes and earthquakes (EQs) constitute another interesting hypothesis based on the observation that VLF radiation is related to seismic activity (Larkina et al., 1983), which was recently confirmed by the DEMETER satellite in (Rozhnoi et al., 2007). Experimental data on high-energy charged particle fluxes, obtained from various near-Earth space experiments (MIR orbital station, METEOR-3, GAMMA and SAMPEX satellites) were processed and analyzed; a 2 to $5 \mathrm{~h}$ precursor effect resulted (Aleksandrin et al., 2003), although its statistical significance was somewhat limited. A re-analysis of the SAMPEX database also shows a $4 \mathrm{~h}$ precursor effect (Sgrigna et al., 2005). The case study of HF wave measurements and gamma rays diagnostic performed on board the CORONAS-I satellite have shown a possible correlation between enhancements of whistler wave activity and soft gamma ray fluxes related to seismic activity (Rothkaehl et al., 2006).

Satellite experiments including Vulkan constellation (Pulinets, 2006), ESPERIA (Sgrigna et al., 2007), CSES (Xuhui et al., 2007) and ARINA (Bakaldin et al., 2007) are aimed to study in detail the seismic effects in the near-Earth magne- tosphere. While Vulkan constellation, ESPERIA and CSES are still at the design level, ARINA has been build and is currently operated on a Resurs-DK1 satellite (Casolino et al., 2008), since 2006 both studied and implemented.

A limitation of these correlation studies is that they have been performed over short time intervals (less than 16 months) compared to the frequency of strong EQs. The NOAA database includes up to 10 years of recording particle data from NOAA-15, nearly eight years from NOAA-16, six years from NOAA-17 and three years from NOAA-18 (Davis, 2007). Therefore, correlations among similar instruments located in more than one satellite can also be studied.

\section{NOAA polar satellites and instruments}

POES circle the Earth in an almost North-South circular orbits, passing close to both poles, with an altitude between 833 (morning orbit) and 870 (afternoon orbit) $\mathrm{km}$. Their orbital period is about $100 \mathrm{~min}$ and they are sun synchronous: NOAA-15 ascending orbit retrievals results in a 07:30 p.m. analysis, and the descending orbits retrievals results in a 07:30 a.m. analysis; NOAA-16 and 18 ascending orbit retrievals results in a 02:00 p.m. analysis, and the descending orbits retrievals results in a 02:00 a.m. analysis; NOAA-17 ascending orbit retrievals results in a 10:00 p.m. analysis, and the descending orbits retrievals results in a 10:00 a.m. analysis (NASA, 2004). Geographically the satellites cover all longitudes and all dipole tilts, while the satellites cover virtually all magnetic latitudes. Due to of the polar orbit, the satellites sample virtually all values of the McIlwain parameter L, although the coverage in $(B, L)$ space, where B is the geomagnetic field, is somewhat limited.

The SEM-2 package was developed primarily to study phenomena in the auroral regions and consists of three different instruments: the Medium Energy Proton and Electron Detector (MEPED) measures energetic electrons and protons mirroring above and precipitating into the high-latitude atmosphere, the Total Energy Detector (TED) measures the total energy flux carried into the atmosphere by particles of auroral energies and the High Energy Proton and Alpha Detector (HEPAD) measures protons and alpha particles, primarily of solar origin. Here we have analysed only MEPED data. Each MEPED consists of two sensor assemblies: the directional (telescope) particle detectors and the omnidirectional proton detectors. Telescopes are mounted in two pairs, one from each pair detects electrons, while the other detects protons and heavier ions. One pair of detectors is mounted to view outward along the Earth-satellite radial vector zenith. At geomagnetic latitudes greater than $30^{\circ}$, these detectors view charged particles that are in the atmospheric loss cone and will enter the atmosphere. The other detector pair is mounted to view at about $80^{\circ}$ compared to the first, and for magnetic latitudes greater than $30^{\circ}$ will measure particles that have pitch angles near $90^{\circ}$. 
The electron detector is a thin $(700 \mu \mathrm{m}) 25 \mathrm{~mm}^{2}$ solidstate detector covered by $0.51 \mu \mathrm{m}$ thick nickel foil, that suppresses detector response to photons and reduces pulse pileup caused by incident low-energy electrons or ions. Electronic pulse-height discrimination is used to select pulses due to incident electrons of nominal energies greater than $30 \mathrm{keV}$, $100 \mathrm{keV}$ and $300 \mathrm{keV}$. The contaminant response to protons that deposit more than $1 \mathrm{MeV}$ in the detector is eliminated electronically. The detectors are, however, sensitive to protons between about $135 \mathrm{keV}$ and $1 \mathrm{MeV}$. Data from the directional proton detectors may be used to correct for this effect.

The proton (ion) detector within each telescope pair is a two-element, solid-state detector telescope. The front element has an effective area of $25 \mathrm{~mm}^{2}$ and thickness of $200 \mu \mathrm{m}$. The back element has an effective area of $50 \mathrm{~mm}^{2}$ and a thickness of $200 \mu \mathrm{m}$. A 2500-gauss magnet is mounted across the input aperture of this detector assembly to prevent any electrons of energies less than $1.5 \mathrm{MeV}$ from reaching the detectors. Electronic pulse height discrimination, together with coincidence logic on the pulses from the two detectors in the telescope, is used to select protons in six energy pass bands (nominally $30-80 \mathrm{keV}, 80-250 \mathrm{keV}, 250$ $800 \mathrm{keV}, 800-2500 \mathrm{keV}, 2500-6900 \mathrm{KeV}$ and $>6900 \mathrm{KeV}$ ) and an integral channel for energies greater than $2.5 \mathrm{MeV}$. This detector is also sensitive to heavy ions (e.g. He and O) although the particle energies defining the pass bands will be marginally higher than those given for protons. The geometric factor for both the electron and proton directional detector systems is $9.5 \times 10^{-7} \mathrm{~m}^{2} \mathrm{sr}$.

The omnidirectional sensors consist of three nominally identical Kevex $\mathrm{Si}(\mathrm{Li})$ solid-state detectors of $50 \mathrm{~mm}^{2}$ area by $3 \mathrm{~mm}$ thickness, independently mounted under spherical shell moderators. Each detector has a full-opening view angle of $120^{\circ}$ in the zenith direction. The detectors are shielded from below by approximately $0.5 \mathrm{~cm}$ of Mallory, and the spacecraft itself provides additional shielding from below. Assuming that it is an isotropic flux the omnidirectional geometric factor would be $0.215 \mathrm{~cm}^{2}$ (Evans and Greer, 2004).

\section{NOAA data preparation}

The NOAA database binary files were downloaded from the NOAA web page http://poes.ngdc.noaa.gov/. A binary file contains a daily archive record and is free to download from the NOAA web page a day after its recording. The archive record comprises (Evans and Greer, 2004) $32 \mathrm{~s}$ of data, including a full set of orbital parameters provided every $8 \mathrm{~s}$ (sub-satellite latitude and longitude every $2 \mathrm{~s}$ ), 16 full data collection cycles from the TED, the MEPED electron and proton telescope instruments and 4 full cycles of the omnidirectional detector sensors. A full set of background data from the 8 TED detector systems is included once in the $32 \mathrm{~s}$ archive record. Finally, a selected portion of the SEM-2 in- strument status, temperature, and system health data as well as data quality and ancillary information are included.

As the amount of NOAA data is large we have used the HBOOK Fortran package for histogramming and fitting, which are developed at CERN. The HBOOK system consists of a few hundred Fortran subroutines which enable the user to symbolically define, fill and output oneand two-dimensional density estimators, under the form of histograms, scatter-plots and tables and to handle Ntuples (Couet and Goossens, 1998). Ntuples is a suitable way of writing micro data-summary-files for further processing, allowing for the projections of individual variables or correlation plots and a selection mechanisms may be defined. The first step in the preparation of NOAA data consists of the transformation of all binary files into Ntuples, making opportune selections and additions of data.

First of all we included in Ntuples only orbital parameters, MEPED and omni-directional data from binary files. The instrument status, temperature, and system health data as well as data quality and ancillary information were used to select the data coming from instrumental errors. Daily average geomagnetic and ionospheric activities were included in the Ntuples with the respective indexes Ap and SID. Data were downloaded respectively from the Indices of Global Geomagnetic Activity of Geo Forschungs Zentrum (GFZ) Postdam at ftp://ftp.gfz-potsdam.de/pub/ home/obs/kp-ap/tab/ and from the American Association of Variable Star Observers (AAVSO) at http://www.aavso.org/ observing/programs/solar/sidbase/. Furthermore, we added the calculus of the minimum mirror point altitudes by the UNILIB libraries (Krunglanski, 2002) to determine if particles were precipitating. The library consists of FORTRAN subroutines which enable computation of the geomagnetic field strength, to evaluate averaged quantities along a drift trajectory and to trace magnetic field lines and drift shells. As well as the widely used $\left(B_{m}, \mathrm{~L}\right)$ coordinates, the library enables evaluation of parameters such as the magnetic field intensity, the McIlwain parameter L, the third adiabatic invariant I, the altitude of the lowest mirror point, etc. (Schmitz et al., 2000).

All sets of orbital parameters are provided every $8 \mathrm{~s}$, so we chose this value as the base time for our study. Consequently all the other variables were defined with respect to the $8 \mathrm{~s}$ step. Thus $8 \mathrm{~s}$ averages of counting rates (CRs), latitude, longitude, MEPED and omni-directional data were calculated. Unreliable CRs with negative values were labeled and excluded from the analysis. Being that the energy detected for the electron is a cumulative sum over three thresholds equal to $E_{1}=30 \mathrm{KeV}, E_{2}=100 \mathrm{KeV}$ and $E_{3}=300 \mathrm{KeV}$, we decided to define new energy channels from the difference of the energies to obtain electrons detected in intervals equal to 30 $100 \mathrm{KeV}, 100-300 \mathrm{KeV}$ and $>300 \mathrm{KeV}$, which is similar to how the proton energies were detected. Also in the case of the new energies stated above, unreliable CRs were defined and excluded when $E_{2}-E_{1}<0$ and when $E_{3}-E_{2}<0$. 

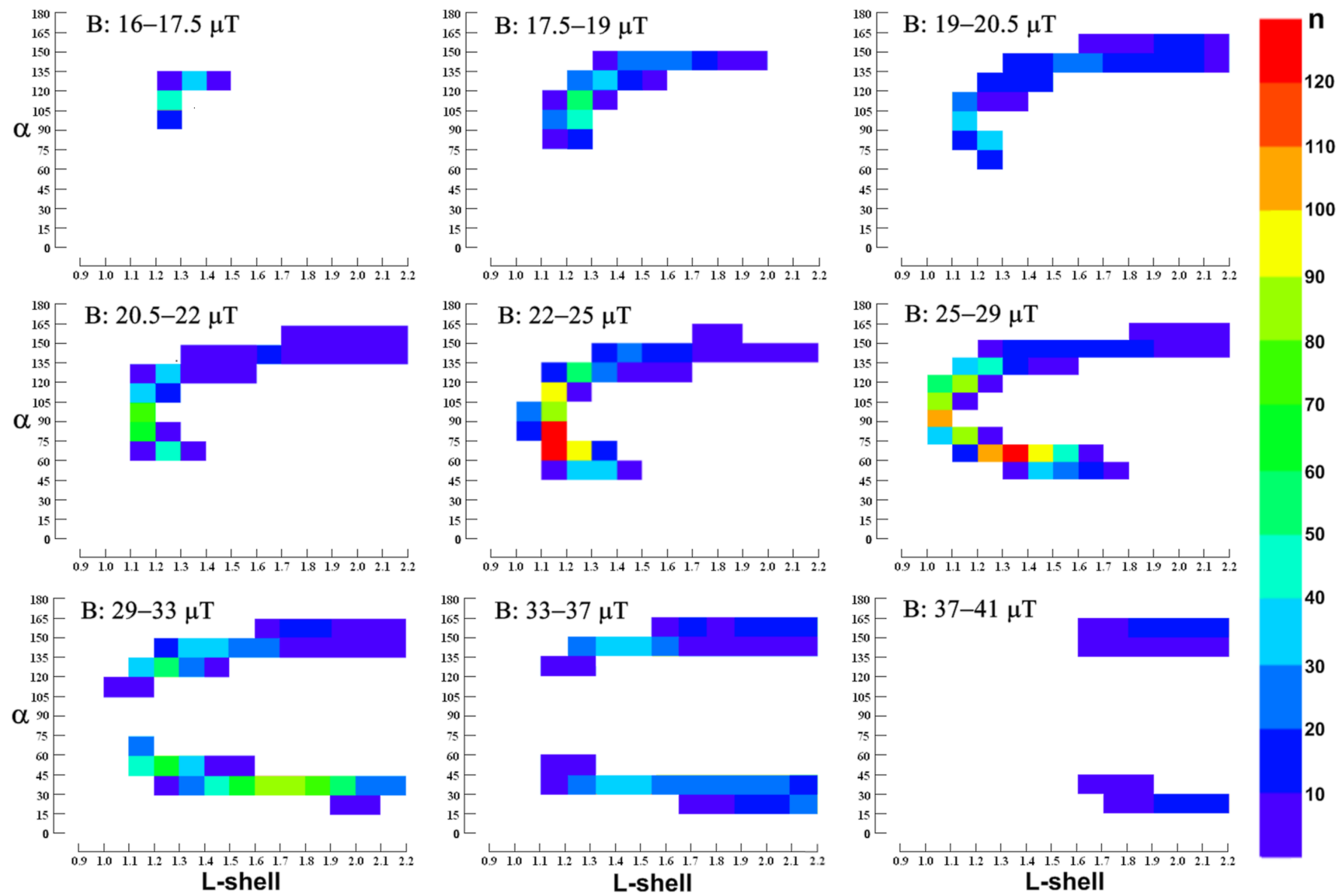

Fig. 1. CR daily average common data cell filling in the adiabatic coordinates on 26 December 2004. $n=$ satellite passes through the same cell.

To correlate seismic activity with NOAA data we built another Ntuple which contains EQs data including: time of events, locations, magnitudes and depths. These data were downloaded from the Earthquake Center of US Geological Survey (USGS) at http://neic.usgs.gov/neis/epic/epic.html. The values of the corresponding L-shells of the EQ epicenter projected to different altitudes were also calculated by UNILIB and included in the Ntuples. This was done to determine the presence and location of a possible link between EQ and particle fluxes.

Finally, after Ntuples were filled, we converted them into ROOT files to compress the data rendering them simpler to manage, study and plot the results using ROOT framework. ROOT is an object-oriented $\mathrm{C}++$ analysis package aimed at solving the data analysis challenges of high-energy physics (Brunet al., 2007) and it is downloadable from the ROOT web site at: http://root.cern.ch/root/Availability.html.

\section{NOAA data analysis}

Sharp, short-term increases in particle CRs ranging from tens of seconds to a few minutes were observed for the first time in the MARIYA experiment, operating on board of the SALYUT-7 orbital station during 1985 (Voronov et al., 1987). It was in that occasion that the term highenergy charged "particle bursts" (PBs) was coined. Our data analysis started from a selection of PBs from the NOAA database. Our analysis method follow the strategy introduced by Sgrigna et al. (2005) but implements some differences. These differences were necessary because, compared to the previously published experiments, NOAA satellites operate at higher orbits and covers different energy range intervals. We calculated the daily averages of CRs and then defined the condition for which a CR fluctuation was not likely due to possible statistical fluctuations with a probability equal to 99\%, the PBs. We then proceeded to fill the Ntuples with the PBs information.

In agreement with a previous work (Sgrigna et al., 2005), the daily averages of CRs were calculated according to their invariants coordinates. In addition, we also considered the 

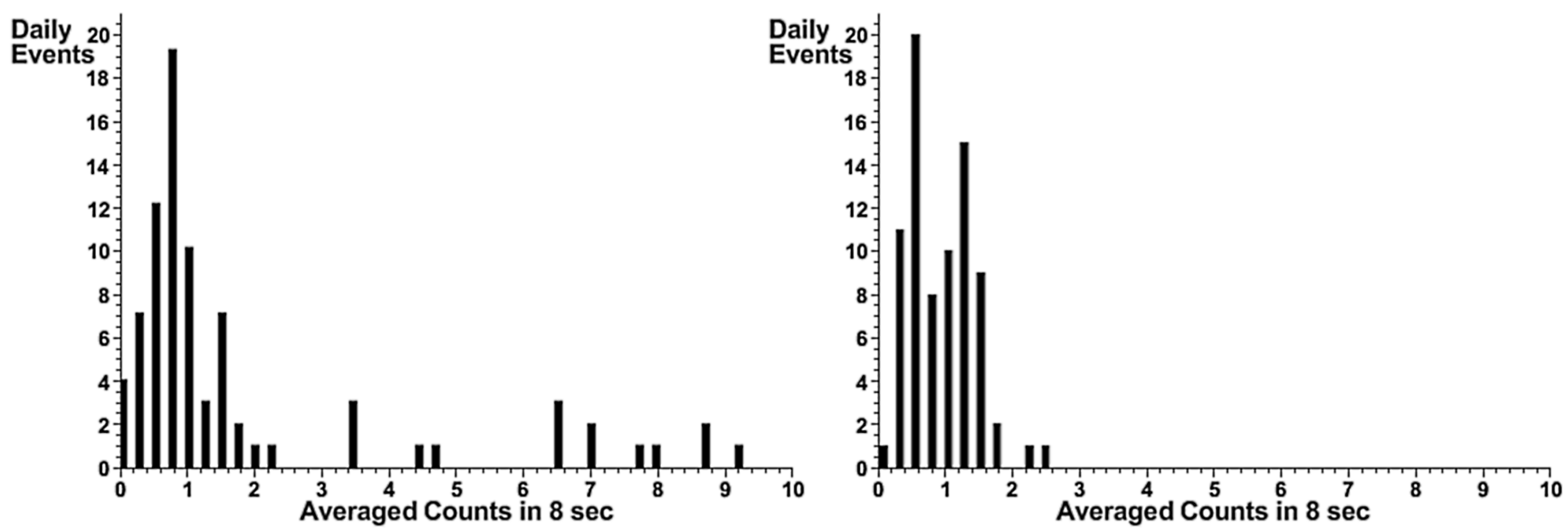

Fig. 2. Distribution of averaged $8 \mathrm{~s}$ counts on 26 December 2004 , for $0^{\circ}$ electrons with energy from $30 \mathrm{KeV}$ to $100 \mathrm{KeV}, 1.1<\mathrm{L}<1.2$ and $90^{\circ}<\alpha<105^{\circ}$. The left distribution was detected outside the SAA with $22 \mu T<\mathrm{B}<25 \mu T$ while the right distribution was detected entering the SAA with $20.5 \mu T<\mathrm{B}<22 \mu T$.

geomagnetic field $\mathrm{B}$ at the satellite locations. It was necessary to take into account the CRs amplitude and variation versus geomagnetic coordinates, because the spatial gradient of particle fluxes near the SAA was too large. In this situation $\mathrm{B}$ can be considered a suitable parameter for delimiting the transition region between inner and outer radiation belts (Walt, 1994) where large gradient are located, sub intervals of the B are defined, so that the CR amplitude variations are limited. The averages were calculated in every sector of a three dimensional matrix divided by L-shell, pitch angle $\alpha$ and B. The L-shell bin was set at 0.1 as in the past cases (Sgrigna et al., 2005) and the range between 0.9 and 2.2 so that we have 13 intervals. In this study the pitch angle is equal to the difference between the particle telescope and geomagnetic field directions. The SEM-2 detectors however, have a finite aperture of $30^{\circ}$ so that we chose a bin of $15^{\circ}$ for a total of 12 intervals. The geomagnetic bin was fixed to be $\mathrm{B}$ dependent with shorter intervals going through the radiation belts, because we needed to compensate for the non linear increase of CRs when the satellite goes through the SAA. The nine B intervals are the following: $16.0-17.5 \mu T, 17.5-$ $19.0 \mu T, 19.0-20.5 \mu T, 20.5-22.0 \mu T, 22.0-25.0 \mu T, 25.0-$ 29.0 $\mu T, 29.0-33.0 \mu T, 33.0-37.0 \mu T$ and 37.0-41.0 $\mu T$. A two dimensional matrix $(\mathrm{L}, \mathrm{B})$ was used to examine particle data of the 4 omni-directional telescopes. In all other cases, we used a three dimensional matrix $(\mathrm{L}, \alpha, \mathrm{B})$. To obtain a reliable statistic we made sure that the satellite passed at least 20 times through the cells with the same intervals for all the variables. We did not consider the CRs and CR daily averages relative to the cells in which satellite passed less than 20 times. Figure 1 shows typical average daily CR data filling of the adiabatic intervals for every geomagnetic cell and the first four pictures are relative to the SAA.

Figure 2 shows typical $8 \mathrm{~s}$ CR distributions inside two different cells; they are compatible with Poisson distributions in agreement with earlier works (Sgrigna et al., 2005). To define the condition for which a CR is a non-poissonian fluctuation with $99 \%$ probability, we introduced the number $n_{\sigma}$ of $\sigma$ that the amplitude $x$ of the CRs must exceed the average $\bar{x}$. In other words we used $n_{\sigma}$ for which $P\left(x>\bar{x}+n_{\sigma} \sigma\right)<0.01$. We had to remember that our amplitudes are the results of an average of four independent variables, so the correct condition for the probability became (Young, 1964)

$P\left(x>\bar{x}+\frac{n_{\sigma} \sigma}{\sqrt{3}}\right)<0.01$.

To obtain $n_{\sigma}$ that satisfy the relation above we considered the tabulated confidence interval for a Poisson distribution (Cowan, 1998). From the upper value of the interval $x_{M}$, which correspond to the probability less than 0.01 , we have

$n_{\sigma}=\frac{x_{M}-\bar{x}}{\sigma}$,

where $\sigma=\sqrt{\bar{x}}$ for a Poisson distribution. Since $\bar{x}$ is not an integer number, we interpolated $n_{\sigma}$ for every value of $\bar{x}$ using a double exponential fitting:

$n_{\sigma}(\bar{x})=n_{o}+n_{1}\left(1-e^{-\bar{x} / x_{1}}\right)+n_{2}\left(1-e^{-\bar{x} / x_{2}}\right) ;$

the behavior of this function is plotted in Fig. 3 .

In order to select the $8 \mathrm{~s} x$ events to be considered as PBs we applied condition in Eq. (1). However, near the SAA region we interpolated the $\bar{x}$ between two cells to have a better precision in the selection algorithm. The interpolation of the points outside the SAA was realized by a linear method while a non-linear bicubic method (Press et al., 2001) was used for the points inside the SAA. Special attention was given to the calculus of first and second derivatives for the interpolation algorithm along the boundary of the $(\mathrm{L}, \mathrm{B})$ subspace.

To confirm reliability of the interpolated averages we developed another method to evaluate the same averages for 


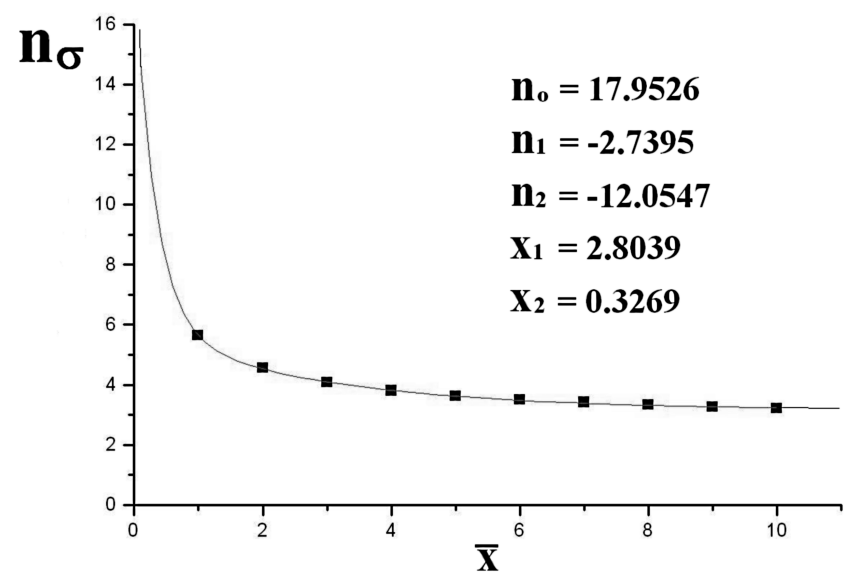

Fig. 3. The double exponential behavior of $n_{\sigma}$ used to select the fluctuations which had $99 \%$ probability to be non-poissonian. The squared point positions were calculated from the tabulate amplitudes of the confidence intervals.

each point on the (L, $\alpha, \mathrm{B})$ space. The idea was to consider a number of cells in the (L, B) subspace so that a more precise definition of average hyper-surface become possible. But, to have such precision we needed a large number of data as one day was not sufficient to assure 20 satellite passages through the very small cells. Given this we used 3 months of data that preceded the day which was examined. The requirement of at least 20 satellite passages through each cell was respected with a division of 130 intervals for $\mathrm{L}$ range multiplied by 100 intervals for B range. In this way, a reliable value of the averages in the regions near SAA can be obtained and selection rules in Eq. (1) can be directly applied. Periods of strong solar activity were also excluded from the 3 months of averaged data, but these were not for the trend due to long periods of solar variations. Hence, the use of a larger portion of the database should be done with great attention. Identical results in PBs selection were obtained using this different method, thereby confirming the results of the previous analysis and rendering them more robust.

The Fortran program filled the new daily Ntuples with both orbital and invariant coordinates, geomagnetic and ionospheric activities, CRs values of all particles and energies, selection rules and PB features. Selected rules are referred to as $\bar{x}$ and $n_{\sigma}$. For the PB features we defined an index which labels PB events and calculated the temporal length of contiguous $\mathrm{PB}$ events together with their average times and amplitudes. Because Van Allen belts are densely populated and strongly influenced by solar activity we are interested in anomalous particle fluxes outside of them. The NOAA satellites go through the Van Allen Belts inside the SAA and polar regions, thus these regions can be excluded by selecting respectively $\mathrm{B}>22 \mu T$ and $\mathrm{L}<2.2$. A summary of the remaining burst activities from the entire 10 year NOAA15 database of electron at $0^{\circ}$ with energy from $30 \mathrm{KeV}$ to $100 \mathrm{KeV}$ is reported in Fig. 4.

\section{NOAA particle bursts and earthquakes}

In Fig. 4 burst activity is shown in black to identify quiet solar periods $(\mathrm{Ap}<16$ and $\mathrm{SID}=1)$ and in gray for the other periods. An inverse correlation appears between the intensity burst and the 11 years solar cycle; an additional correlation between the PBs and the the boreal summer is also seen. Concerning the sun activity flags those conditions will be carefully analysed in future work. For instance a feature to analyse is the connection between sudden phase anomalies in VLF transmitters and solar x-ray which was observed to be more influential at the time of minimum solar activity (Raulin et al., 2006). On the other hand, strong solar storms influence the ionosphere up to several days after the solar event that generated them (Baker and Kanekal, 2008). Furthermore geomagnetic storms can begin or finish at the end of the previous day or during the early hours of the subsequent day respectively. The Ap averages over these days could then be lower than 16 while at the same time solar activity can still influence the ionosphere.

To better define the particles that are affected by external perturbations we need to verify if they are precipitating particles (Sgrigna et al., 2005). Particle precipitation from the lower boundary of the radiation belts can be described as a result of pitch-angle diffusion and drifting around the Earth along L-shell (Abel and Thorne, 1998a,b). In this process the altitude of the bouncing points falls and when the particles go below $100 \mathrm{~km}$ they interact with the atmosphere and are lost. Through the UNILIB subroutines we calculated the minimum L-shell bouncing altitude $H_{\text {mirr }}$ and recorded them in the Ntuples so we can now select particle precipitation events by the condition $H_{\text {mirr }}<100 \mathrm{~km}$.

At the beginning we initially considered only stronger seismic events since larger effects are expected in the ionosphere. For example, ionospheric anomalies close to the Sumatra EQ on 26 December 2004, were detected using magnetic and electron density data (Balasis and Mandea, 2007). By using the method discussed here, we observe anomalous PB activity in the NOAA-15 electron data $\left(0^{\circ}\right.$, $30 \mathrm{KeV}$ to $100 \mathrm{KeV}$ ) during December 2004, an high number of burst appear on 26 December. For this period we also took into account the short time behavior of Ap index (3h) to analyse in detail the burst dependence on solar activity. Black and gray bursts in Fig. 5 were selected in the same way as in Fig. 4. But now on Fig. 5 (left) we can distinguish black dashed PBs with daily Ap $<16$ but Ap $>24$ for at least $3 \mathrm{~h}$, they were on $1,5,11,13,16,18$ and 21 December. We can also distinguish gray dashed PBs with daily $\mathrm{Ap}<16$ and $\mathrm{Ap}<25$ for all the day but $\mathrm{SID}=1$, they were on 2, 7, 19, 23, 27 and 31 December. Figure 5 on the right shows the results of the same analysis using $30 \mathrm{~min}$ time intervals and helps us to evaluate the importance of PBs on December 13 and 21. They are concentrated over a few hours and could be linked to the $3 \mathrm{~h}$ Ap index hight values on the same days. With reference to the mean number of bursts in December 

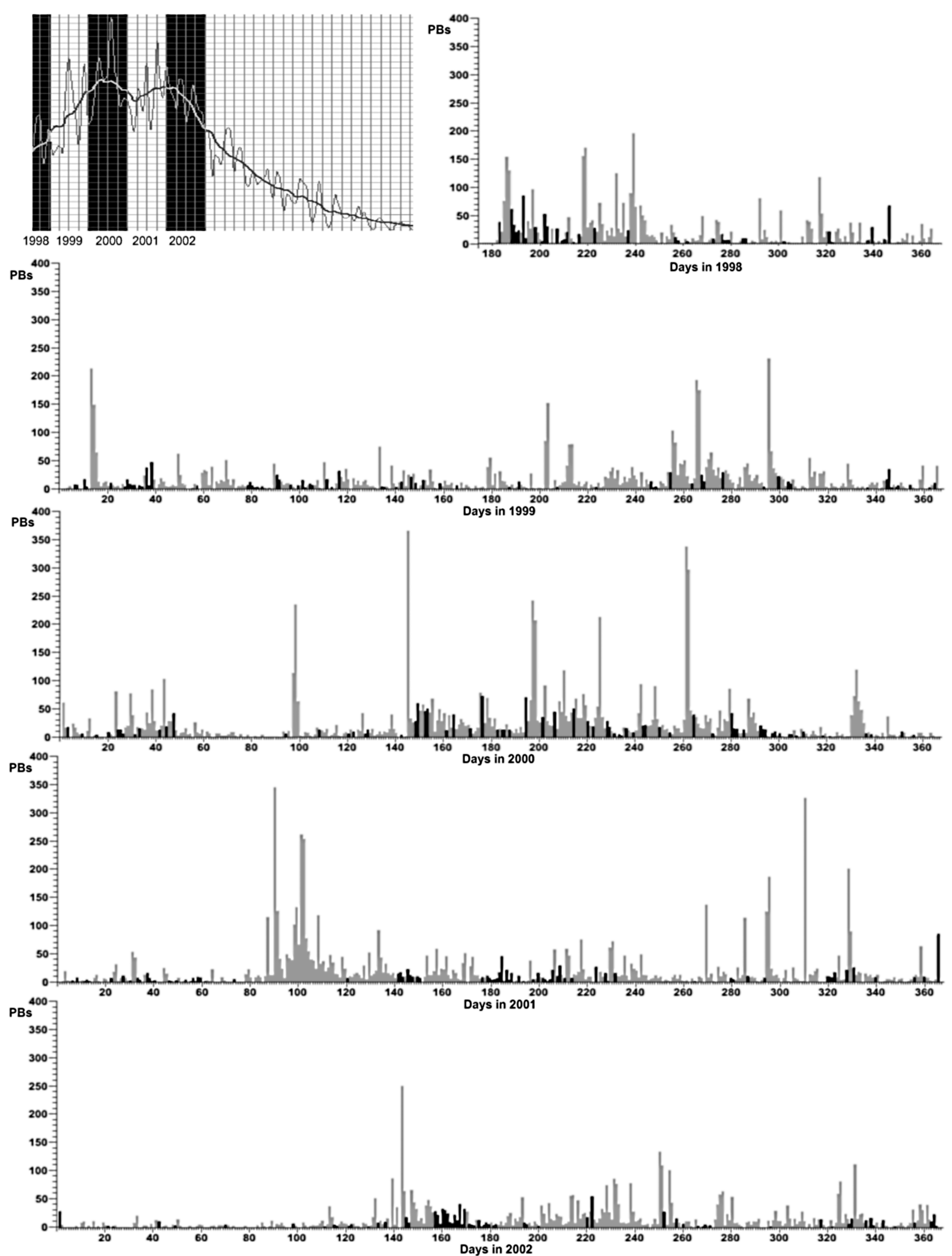

Fig. 4. A decade of PB selection from the NOAA-15 database during quiet solar days with $A p<16$ and SID=0 (in black) and during the resting days (in gray). Solar Cycle 23 was also reported for a comparison. 


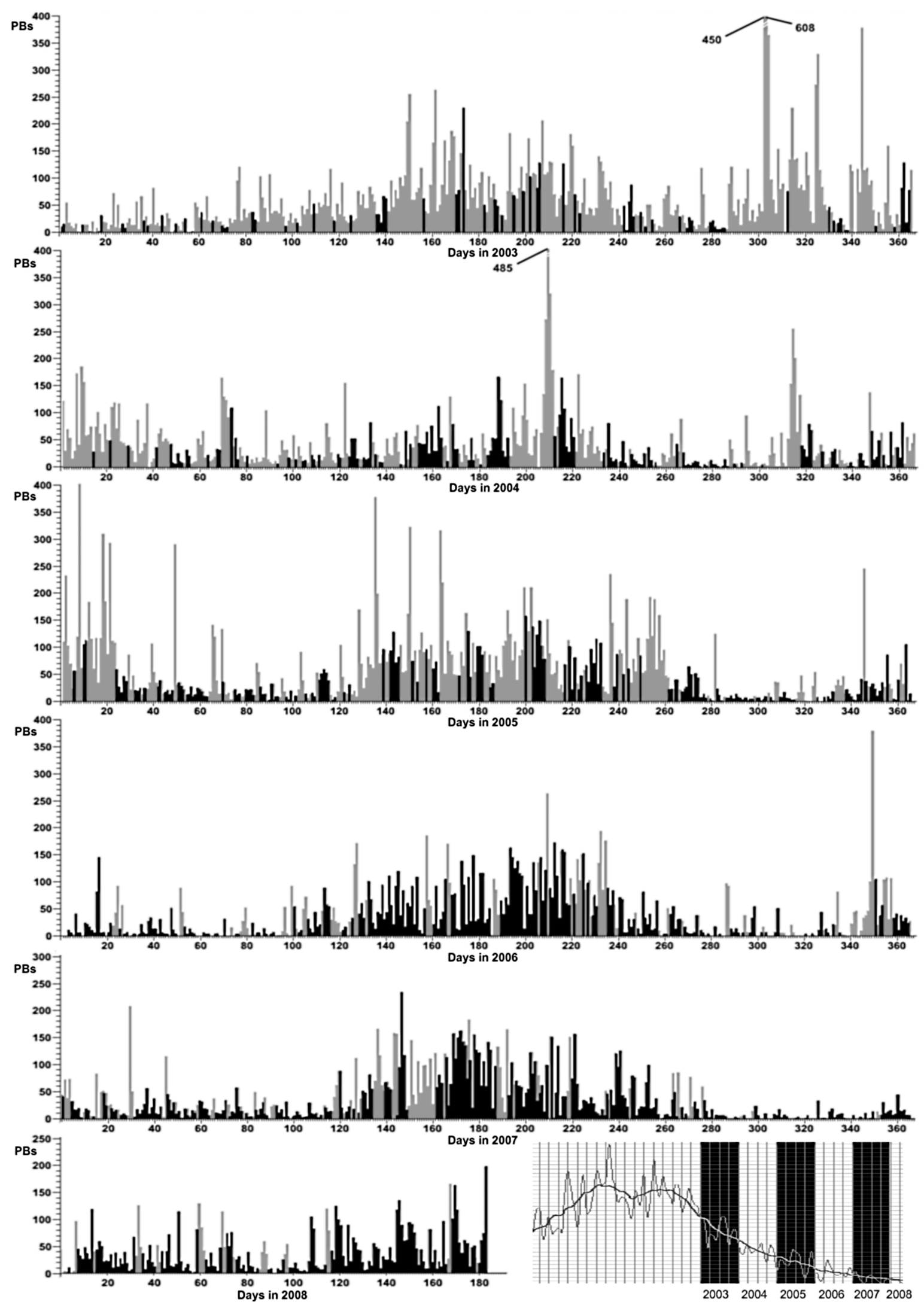

Fig. 4. Continued. 

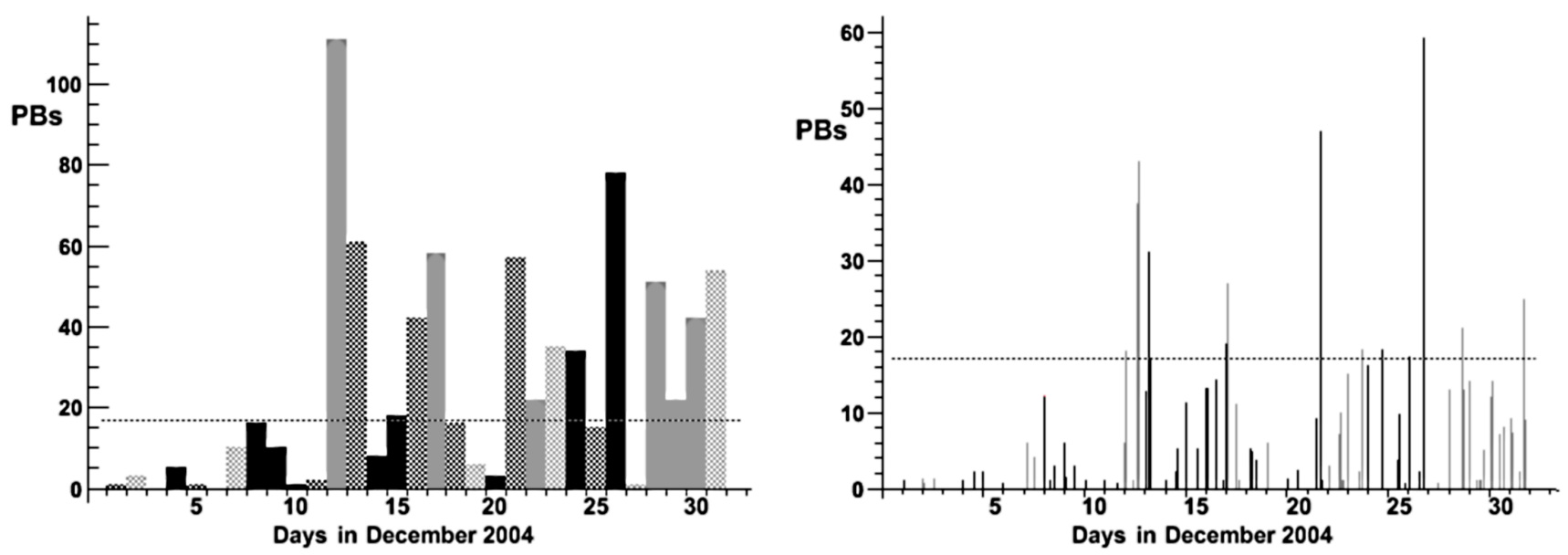

Fig. 5. The PB selection in the December 2004 NOAA-15 database. Black and gray PBs were selected in the same way as in Fig. 4. Black dashed PBs were selected on days with daily averages of $\mathrm{Ap}<16$ and with at least one of the 8 three hour periods where Ap $>25$. Gray dashed PBs were selected on days with SID activity. The horizontal dashed line is the monthly quiet solar period PB average. In the left graph we chose a $24 \mathrm{~h}$ intervals to show the daily PB sums while for the right graph we chose half-hour intervals to show the detailed PBs importance and their temporal distribution.

2004 (horizontal dashed line) we can see that the SID activity produced unimportant PB numbers on days 2, 7, 19, 23, 27 and 31.

We tested the algorithm over a longer period and applied the PBs selection from 1 September 2004, to 31 December 2004. The PB activity measured by the three satellites together with the global seismic activity are shown in Fig. 6 . During this long period strong and moderate geomagnetic perturbations were recorded. Ap index went above 100 at the beginning of November 2004 and many days of perturbed particle fluxes were reported (Lekshmi, 2008). The period 211 November was characterised by activity which generated two X-class X-ray flares (Yermolaev et al., 2005) and weak geomagnetic activity was recorded in 5 December (Tverskaya et al., 2006). On 27 December 2004, at 21:30:26.5 UT, a giant hard X-ray/g ray flare, near the solar zenith, ionized the exposed part of Earths dayside ionosphere (Inan et al., 2007c). We stopped at the end of December 2004, since the month of January 2005 was perturbed by several ionospheric phenomena (Longden et al., 2007) which were associated with at least seven moderate or weak storms (Tverskaya et al., 2006). Days with high solar activity were excluded when we searched for any possible connection with seismic events and were labeled in grey in all the figures here. The top plot in Fig. 6 shows the geomagnetic activity during period by means of Ap and SID indexes. The dotted line in the Ap plot is the threshold and is equal to 16 while the grey bands represent days with $\mathrm{SID}=1$.

Differently from Figs. 4 and 5, to search for a correlation with strong seismic activity, in Fig. 6 we defined black PBs only during quiet days (QDs) when the daily averages of $\mathrm{Ap}<16, \mathrm{Ap}<25$ in each of the three hour intervals during the same day and $\mathrm{SID}=0$. We labeled all the other PBs in gray. We focus on EQs having a magnitude larger than 6.5. Exceptional number of PBs measured by at least one satellite were observed during QDs on 6, 8 and 29 September, 10 October, 16 and 26 November, 26 December; for each of this days significant seismic activity was also observed. NOAA-16 seems to be more sensitive to September and October EQs while NOAA-15 and 17 are more sensitive during the months of November and December. Due to the limited coverage of each satellite, PB activity appears different from the three considered databases; a sum of three PBs database could be more appropriate and is plotted in logarithmic scale plot in Fig. 6. We extend this analysis to long periods.

We considered all the EQs in the Indonesian region where magnitude was larger or equal to 7.0; this includes about 35 EQs starting from 1998. The reason behind this was that we started observing the first ever PBs on the occasion of the great Sumatra EQ in 2004. However, we could not observe PBs in other strong events occurring in different regions. So, because over the last decade Indonesian EQs have been reported to be the world's strongest and most frequent, we decided to examine Indonesian events. For these EQs we list in Table 1 the following quantities: magnitude, date and time in universal time (UT), location and depth. A monthly PBs average was defined as the PBs average number during quiet solar periods in that month, it is also reported in Table 1. Twelve EQs occurred in periods of not QDs and they are labeled with one $*$. Seven EQs occurred during the solar maximum; during this period the number of $\mathrm{PBs}$ was significantly lower. Three EQs on 26 December 2004, $M=7.5$, on 12 September 2007, $M=8.1$ and on 13 September 2007, $M=7.2$, occurred after stronger initial seismic events and are considered strong aftershocks. Five EQs were associated with a number of PBs which was comparable to the 

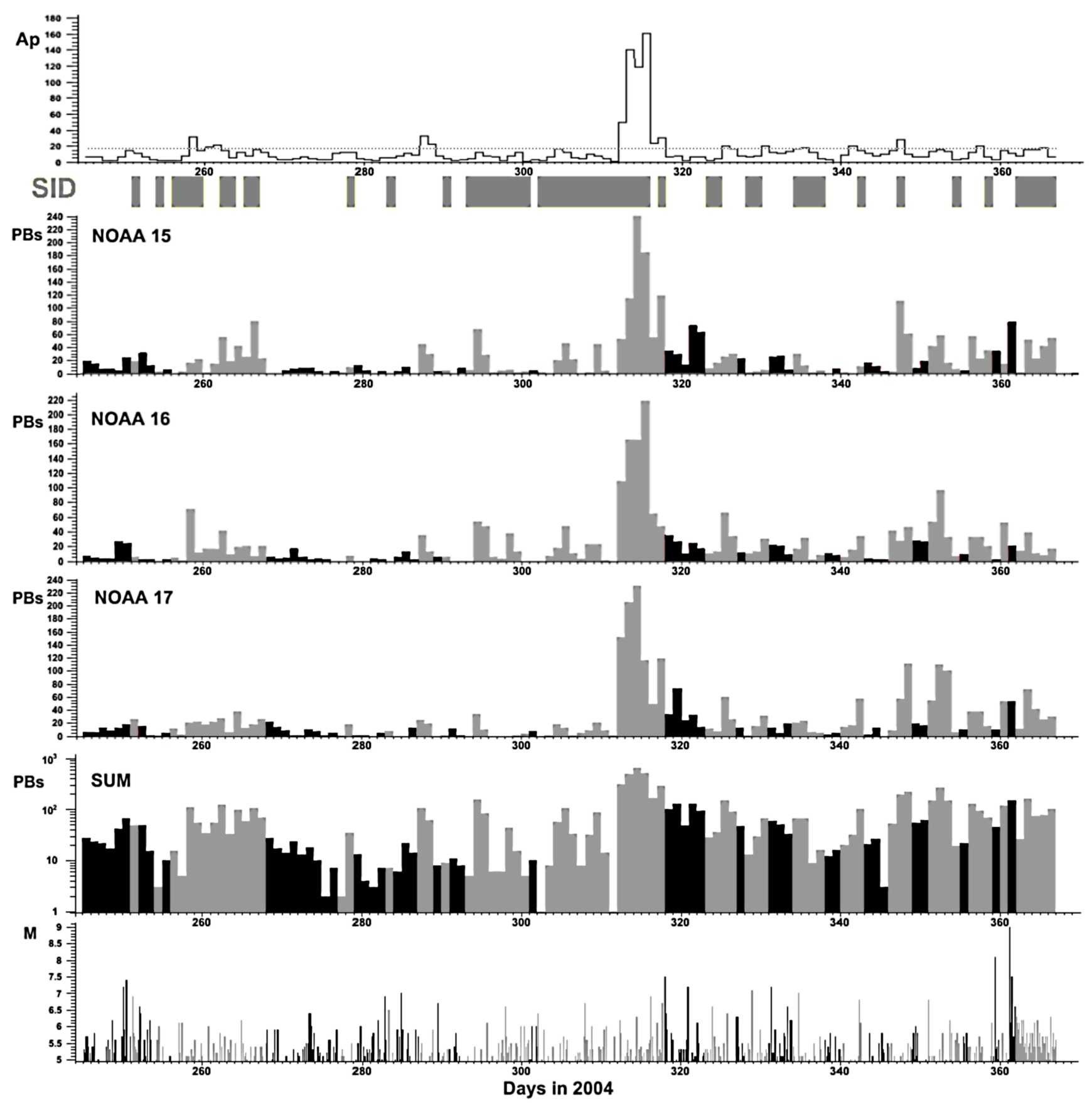

Fig. 6. The NOAA-15, 16 and 17 PB daily activities and their total sum compared with Ap and SID indexes (on the top) and global seismic activity (on the bottom) over the same period of 1 September to 31 December 2004. Black PBs were selected on QDs. Seismic activity was included when magnitude $>5$. 
Table 1. Strong earthquakes with magnitude $\mathrm{M} \geq 7.0$ in the $10^{\circ} \mathrm{N}$ to $10^{\circ} \mathrm{S}$ and $90^{\circ} \mathrm{E}$ to $140^{\circ} \mathrm{E}$ region from $1 \mathrm{July} 1998$ to $30 \mathrm{June} 2008$. $(-)$ means the satellite was not active yet, $\left({ }^{*}\right)$ means non QD and only one $\left(^{*}\right)$ means three non QDs: the day before, the day of and the day after the EQ.

\begin{tabular}{|c|c|c|c|c|c|c|c|c|c|}
\hline M & $\begin{array}{l}\text { Date } \\
\text { (UT) }\end{array}$ & Latitude & Longitude & $\begin{array}{l}\text { Depth } \\
(\mathrm{Km})\end{array}$ & $\begin{array}{l}\text { Daily \#PB } \\
\text { Average }\end{array}$ & $\begin{array}{l}\text { NOAA-15 } \\
\text { \#PB }\end{array}$ & $\begin{array}{l}\text { NOAA-16 } \\
\text { \#PB }\end{array}$ & $\begin{array}{l}\text { NOAA-17 } \\
\text { \#PB }\end{array}$ & $\begin{array}{l}\text { NOAA-18 } \\
\text { \#PB }\end{array}$ \\
\hline 7.1 & $28 / 10 / 1998$ 16:25 & $0.84^{\circ} \mathrm{N}$ & $125.97^{\circ} \mathrm{E}$ & 33 & 5 & $*, *, 3$ & - & - & - \\
\hline 7.0 & 09/11/1998 05:38 & $6.92^{\circ} \mathrm{S}$ & $128.95^{\circ} \mathrm{E}$ & 33 & 1 & $*$ & - & - & - \\
\hline 8.3 & 29/11/1998 14:10 & $2.07^{\circ} \mathrm{S}$ & $124.89^{\circ} \mathrm{E}$ & 33 & 1 & $*$ & - & - & - \\
\hline 7.1 & 04/03/1999 08:52 & $5.40^{\circ} \mathrm{N}$ & $121.94^{\circ} \mathrm{E}$ & 33 & 2 & $*$ & - & - & - \\
\hline 7.6 & 04/05/2000 04:21 & $1.11^{\circ} \mathrm{S}$ & $123.57^{\circ} \mathrm{E}$ & 26 & 19 & $*$ & - & - & - \\
\hline 8.3 & $04 / 06 / 200016: 28$ & $4.72^{\circ} \mathrm{S}$ & $102.09^{\circ} \mathrm{E}$ & 33 & 14 & * & - & - & - \\
\hline 7.1 & 28/08/2000 19:29 & $4.12^{\circ} \mathrm{S}$ & $127.03^{\circ} \mathrm{E}$ & 33 & 12 & $*$ & - & - & - \\
\hline 7.5 & 01/01/2001 06:57 & $6.90^{\circ} \mathrm{N}$ & $126.58^{\circ} \mathrm{E}$ & 33 & 4 & $0,0, *$ & - & - & - \\
\hline 7.4 & $13 / 02 / 200119: 28$ & $4.68^{\circ} \mathrm{S}$ & $102.56^{\circ} \mathrm{E}$ & 36 & 3 & $0, *, *$ & $0, * *$ & - & - \\
\hline 7.1 & $24 / 02 / 200107: 23$ & $1.27^{\circ} \mathrm{N}$ & $126.25^{\circ} \mathrm{E}$ & 35 & 3 & $0,0,3$ & $2,0,1$ & - & - \\
\hline 7.5 & $19 / 10 / 200103: 28$ & $4.10^{\circ} \mathrm{S}$ & $123.91^{\circ} \mathrm{E}$ & 33 & 4 & $*, *, 0$ & $*, *, 0$ & - & - \\
\hline 7.5 & 05/03/2002 21:16 & $6.03^{\circ} \mathrm{N}$ & $124.24^{\circ} \mathrm{E}$ & 31 & 3 & $0, *, *$ & $1, *, *$ & - & - \\
\hline 7.7 & $10 / 10 / 200210: 50$ & $1.76^{\circ} \mathrm{S}$ & $134.30^{\circ} \mathrm{E}$ & 10 & 1 & $*$ & $*$ & $*$ & - \\
\hline 7.6 & 02/11/2002 01:26 & $2.82^{\circ} \mathrm{N}$ & $96.08^{\circ} \mathrm{E}$ & 30 & 1 & $*$ & $*$ & $*$ & - \\
\hline 7.1 & $26 / 05 / 2003$ 19:23 & $2.35^{\circ} \mathrm{N}$ & $128.85^{\circ} \mathrm{E}$ & 31 & 41 & $*$ & $*$ & $*$ & - \\
\hline 7.1 & 05/02/2004 21:05 & $3.62^{\circ} \mathrm{S}$ & $135.54^{\circ} \mathrm{E}$ & 16 & 17 & $*$ & $*$ & $*$ & - \\
\hline 7.5 & $07 / 02 / 200402: 42$ & $4.00^{\circ} \mathrm{S}$ & $135.02^{\circ} \mathrm{E}$ & 10 & 17 & $*, 0, *$ & $*, 0, *$ & $*, 0, *$ & - \\
\hline 7.3 & $25 / 07 / 200414: 35$ & $2.43^{\circ} \mathrm{S}$ & $103.98^{\circ} \mathrm{E}$ & 582 & 32 & $*$ & $*$ & $*$ & - \\
\hline 7.5 & $11 / 11 / 200421: 26$ & $8.15^{\circ} \mathrm{S}$ & $124.87^{\circ} \mathrm{E}$ & 10 & 25 & $*$ & $*$ & $*$ & - \\
\hline 7.1 & $26 / 11 / 200402: 25$ & $3.57^{\circ} \mathrm{S}$ & $135.35^{\circ} \mathrm{E}$ & 10 & 25 & $*, 26,27$ & $*, 23,21$ & $*, 14,5$ & - \\
\hline 9.1 & $26 / 12 / 200400: 58$ & $3.30^{\circ} \mathrm{N}$ & $95.98^{\circ} \mathrm{E}$ & 30 & 17 & $*, 78, *$ & $*, 20, *$ & $*, 53, *$ & - \\
\hline 7.5 & $26 / 12 / 200404: 21$ & $6.91^{\circ} \mathrm{N}$ & $92.96^{\circ} \mathrm{E}$ & 39 & 17 & $*, 78, *$ & $*, 20, *$ & $*, 53, *$ & - \\
\hline 7.1 & $05 / 02 / 200512: 23$ & $5.29^{\circ} \mathrm{N}$ & $123.34^{\circ} \mathrm{E}$ & 525 & 19 & $*, 22, *$ & $*, 22, *$ & $*, 8, *$ & - \\
\hline 7.1 & 02/03/2005 10:42 & $6.53^{\circ} \mathrm{S}$ & $129.93^{\circ} \mathrm{E}$ & 201 & 12 & $22,18,10$ & $18,9,4$ & $33,26,24$ & - \\
\hline 8.6 & 28/03/2005 16:09 & $2.09^{\circ} \mathrm{N}$ & $97.11^{\circ} \mathrm{E}$ & 30 & 12 & $27,8,12$ & $9,1,1$ & $4,11,12$ & - \\
\hline 7.5 & $24 / 07 / 200515: 42$ & $7.92^{\circ} \mathrm{N}$ & $92.19^{\circ} \mathrm{E}$ & 16 & 84 & $57,98,128$ & $25,50,76$ & $73,56,69$ & $35,40,140$ \\
\hline 7.6 & $27 / 01 / 200616: 58$ & $5.47^{\circ} \mathrm{S}$ & $128.13^{\circ} \mathrm{E}$ & 397 & 10 & $*, 2,4$ & $*, 3,4$ & $*, 17,14$ & $*, 2,8$ \\
\hline 7.7 & 17/07/2006 08:19 & $9.28^{\circ} \mathrm{S}$ & $107.42^{\circ} \mathrm{E}$ & 20 & 72 & $102,107,13$ & $79,36,15$ & $61,29,30$ & $98,23,23$ \\
\hline 7.5 & $21 / 01 / 200711: 27$ & $1.07^{\circ} \mathrm{N}$ & $126.28^{\circ} \mathrm{E}$ & 22 & 15 & $21, *, 12$ & $34, *, 13$ & $14, *, 3$ & $43, *, 15$ \\
\hline 7.5 & 08/08/2007 17:05 & $5.86^{\circ} \mathrm{S}$ & $107.42^{\circ} \mathrm{E}$ & 280 & 46 & $*, 69,141$ & $*, 27,126$ & $*, 36,15$ & $*, 21,7$ \\
\hline 8.5 & 12/09/2007 11:10 & $4.44^{\circ} \mathrm{S}$ & $101.37^{\circ} \mathrm{E}$ & 34 & 24 & $16,21,36$ & $13,23,25$ & $0,14,0$ & $8,22,1$ \\
\hline 8.1 & $12 / 09 / 200723: 49$ & $2.62^{\circ} \mathrm{S}$ & $100.84^{\circ} \mathrm{E}$ & 35 & 24 & $16,21,36$ & $13,23,25$ & $0,14,0$ & $8,22,1$ \\
\hline 7.2 & 13/09/2007 03:35 & $2.13^{\circ} \mathrm{S}$ & $99.63^{\circ} \mathrm{E}$ & 22 & 24 & $21,36,4$ & $23,25,7$ & $14,0,0$ & $22,1,0$ \\
\hline 7.5 & 20/02/2008 08:08 & $2.77^{\circ} \mathrm{S}$ & $95.96^{\circ} \mathrm{E}$ & 26 & 25 & $108,17,2$ & $69,16,3$ & $23,10,10$ & $23,7,3$ \\
\hline 7.3 & $25 / 02 / 200808: 36$ & $2.49^{\circ} \mathrm{S}$ & $99.97^{\circ} \mathrm{E}$ & 25 & 25 & $0,0,1$ & $0,0,0$ & $15,1,0$ & $1,0,0$ \\
\hline
\end{tabular}

monthly PBs average during quiet solar periods. The 8 remaining EQs were associated with an exceptional number of PBs for the period where they were recorded.

We also studied more in details the properties of of PBs associated with EQs: intensity, geographic and temporal distributions, L-shell and pitch angle. For instance in Fig. 7 we show the PBs detected in connection with two strong EQs in the Sumatra region on 26 December 2004 and on 20 February 2008. In the first case cluster of PBs were recorded about $35 \mathrm{~min}, 12$ and $17 \mathrm{~h}$ after the big quake; while their geographic position is consistent with eastward drifting precipitating electrons. This is due to the fact that SAA functions like a drain pipe for precipitating particles in the atmosphere, because it defines a cut on the geographical longitude which captures electrons from the West and protons from the East. The intensity distribution of these PBs is plotted in Fig. 7 on the right; we note that the detected PBs are belonging to three distinct fluxes anomalies on an otherwise flat low rate background. PBs that occurred in connection with the second EQ made clusters recorded about 20,17.5, 17 and $9 \mathrm{~h}$ before the seismic event. Their geographic positions are also in this case consistent with eastward drifting precipitating electrons. The intensity distribution of these PBs is plotted on Fig. 8 on the right. Here, one can note that the detected PBs form six better distinct flux anomalies on an otherwise flat low rate background. 


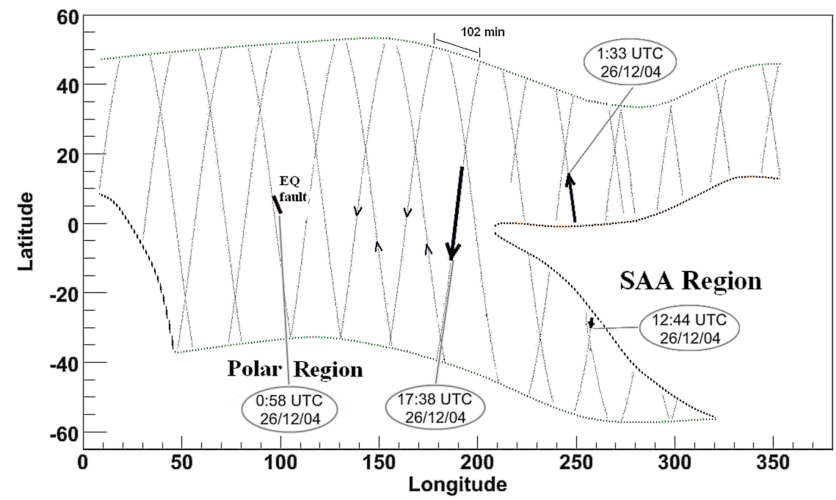

PBs December 26, 2004 - Sumatra event 26/12/2004
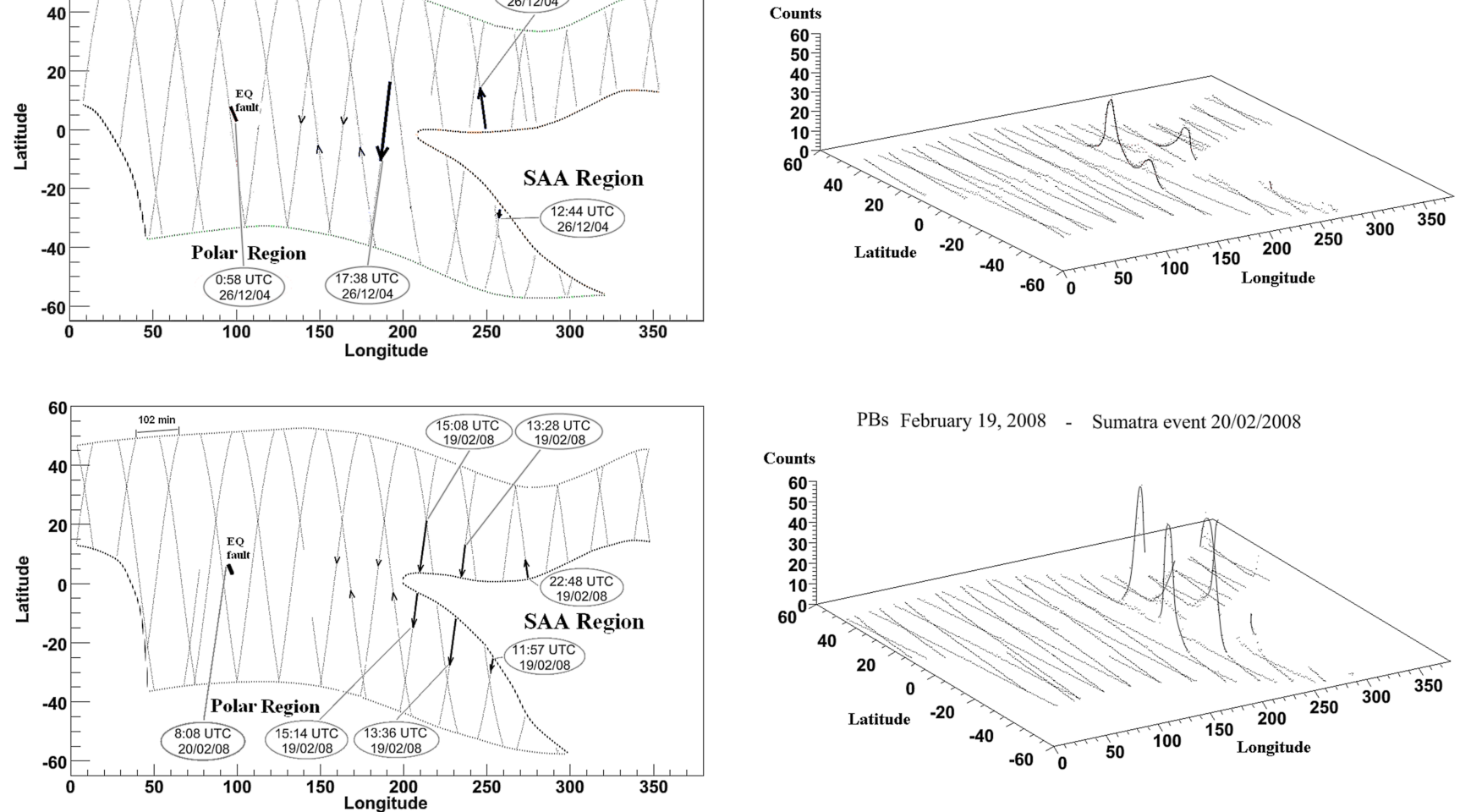

PBs February 19, 2008 - Sumatra event 20/02/2008

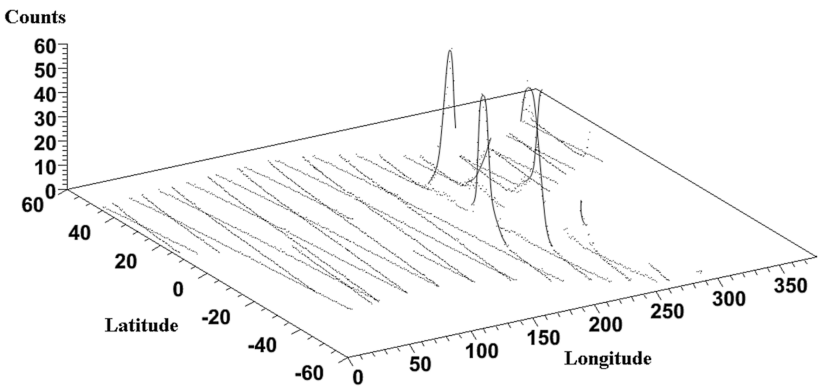

Fig. 7. The NOAA-15 orbits, PBs geographical distribution, PB times with respect to the Sumatra EQ times and fault positions (on the left), and the NOAA-15 PB count dynamic (on the right) are shown in two cases. In the first case we can only observe post-seismic PBs while in the second we can observe pre-seismic PBs. Bold lines define the selection of particle precipitation outside the SAA while the dotted lines indicate the polar regions with $\mathrm{L}>2.2$ and arrows define the direction of the satellite motion.

L-shell and pitch angle distributions in Fig. 8 are of the same period as those distributions in Fig. 6 but here we plotted only solar quiet periods for a better visualization. They are not normalized by the time spent at the various L-shells. We have observed that the PBs induced by solar activity have a higher L-shell value than those observed in PBs near the times of EQs. In fact, particle precipitation due to external influence propagates inside the Van Allen Belts leading to PBs that fall from the top to the bottom of L-shell. PB L-shells are concentrated in the 1.1-1.2 interval on 26 December, this could be considered an index of internal influence on particle precipitation. The pitch angle is in the $60-75^{\circ}$ region, thus confirming the particle precipitation hypothesis. PB L-shells and pitch angles on 19 February 2008 are identical to those on 26 December 2004.

Also PBs of NOAA-16 and 17, detected after the big quake, were observed on geographical locations near the SAA border. PBs studied above regard $0^{\circ}$ electrons with energies between $30 \mathrm{KeV}$ and $100 \mathrm{KeV}$, no exceptional number of PBs were detected by the other channels of electrons, protons and omni-directional detectors.

\section{Conclusions}

We have studied for the first time the NOAA particle database in connection with global seismic activity. Additionally, we have for the first time detected PBs using multiple satellites with identical detectors.

We developed a selection algorithm for PBs suited for NOAA data but different from that used in earlier studies (Sgrigna et al., 2005). The statistical analysis used to identify PBs is made by an accurate method to calculate and interpolate average CRs at every point of invariant space. This method seems to work also in the SAA, polar and transitions belts regions. This analysis could be used to study the process that connects the different ionosphere zones with sun activity, thunderstorms, cosmic rays and other phenomena, by means of PB activity.

The ten years PB plot in Fig. 4 clearly shows anticorrelation with respect to the 11 years solar cycle. The anticorrelation is detectable both in the number of the PBs and in the number of days they appear. However, we must remember that the number of days they appear are quiet solar periods which are linked to the solar activity through the 


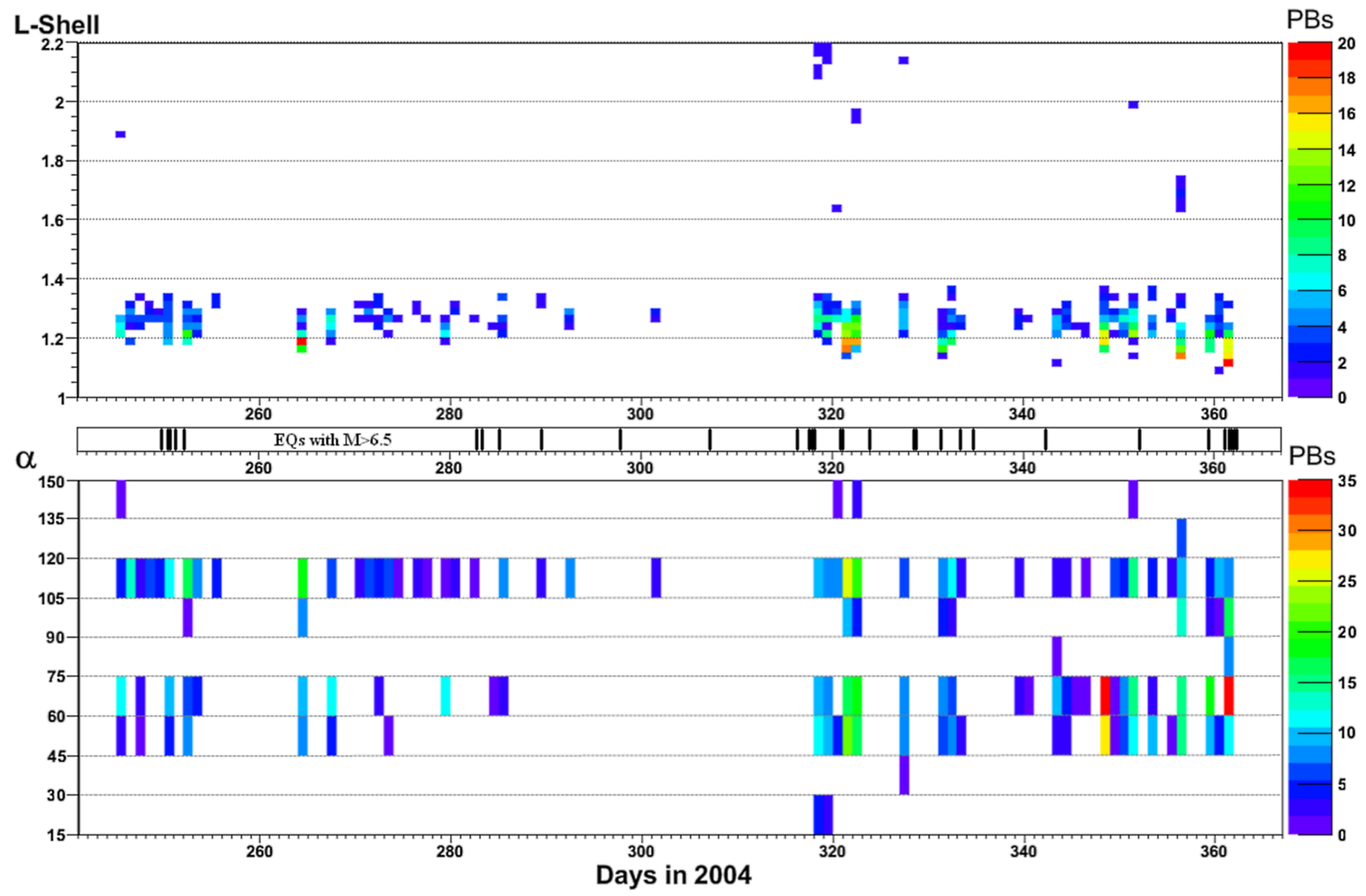

Fig. 8. L-shells and pitch angles $\alpha$ of PBs from 1 September to 31 December 2004, on days with average Ap $<16$ and SID=0. Colors indicate the number of PBs for every interval of considered variables. EQs with $\mathrm{M} \geq 6.5$ are also indicated by vertical bands between $\mathrm{L}-\mathrm{shell}$ and $\alpha$ plots.

geomagnetic restrictions described in Sect. 5. PB activity increases during the boreal summer at the minimum of the solar cycle.

The analysis of the $0^{\circ}$ electron channel with energy between $30 \mathrm{KeV}$ and $100 \mathrm{KeV}$ shows exceptional numbers of PBs with respect to the monthly PB average during quiet solar periods. This is in connection with the Sumatra EQ and some of the largest $(\mathrm{M}>7)$ quakes that struck the Indonesian region over the last ten years. The corresponding PBs are observed near the SAA west boundary in the transition region between the inner and outer radiation belts. PB intensities were of the order of $10-100$ particle counts every $8 \mathrm{~s}$ for Lshell between 1.1 and 1.2 having a pitch angle of about 60 to $75^{\circ}$, consistent with the precipitation hypothesis. The total time length of continuous PB sequences was from about a few seconds to a few minutes.

From this analysis it appears that there is a strong influence of the solar activity on the PB activity. A significant improvement in this analysis should include a more accurate usage of the detail time structure of both Ap and SID indexes.
Given the limited number of EQs examined here, further research is needed to determine whether PBs are correlated with EQs, in particular to verify if the definition of $P B$ we used is suitable to search for correlation with EQs.

Acknowledgements. We would like to thank S. Pulinets and M. Casolino for their precious observations and corrections. Additionally, we would also like to thank L. Conti for his valuable input regarding particle precipitation. Finally, our thanks go to G. Esposito, R. Gallaccio and P. Zuccon for their help pertaining to hbook and UNILIB programming solutions. We also gratefully recognise the grant from Consulta delle Fondazioni delle Casse di Risparmio Umbre, which has been instrumental for the study presented in this paper.

Edited by: P. F. Biagi

Reviewed by: M. Casolino and S. Pulinets 


\section{References}

Abel, B. and Thorne, R. M.: Electron scattering loss in Earths inner magnetosphere 1, Dominant physical processes, J. Geophys. Res., 103(A2), 2385-2396, 1998a.

Abel, B. and Thorne, R. M.: Electron scattering loss in Earths inner magnetosphere 2, Sensitivity to model parameters, J. Geophys. Res., 103(A2), 2397-2407, 1998b.

Aleksandrin, S., Yu, Galper, A. M., Grishantzeva, L. A., et al.: High-energy charged particle bursts in the near-Earth space as earthquake precursors, Ann. Geophys., 21, 597-602, 2003, http://www.ann-geophys.net/21/597/2003/.

Asikainen, T. and Mursula, K.: Energetic electron flux behavior at low L-shells and its relation to the South Atlantic Anomaly, J. Atmos. Sol.-Terr. Phys., 70, 532-538, doi:10.1016/j.jastp.2007.08.061, 2008.

Bakaldin, A. V., Batishchev, A. G., Voronov, S. A., et al.: Satellite Experiment ARINA for Studying Seismic Effects in the HighEnergy Particle Fluxes in the Earths Magnetosphere, Cosmic Res., 45, 5, 445-448, 2007.

Baker, D. N.: Effects of the Sun on the Earth's environment, J. Atmos. Sol.-Terr. Phys., 62, PII: S1364-6826(00)00119-X, 1669_ 1681, 2000.

Baker, D. N. and Kanekal, S. G.: Solar cycle changes, geomagnetic variations, and energetic particle properties in the inner magnetosphere, J. Atmos. Sol.-Terr. Phys., 70, 195-206, doi:10.1016/j.jastp.2007.08.031, 2008.

Balasis, G. and Mandea, M.: Can electromagnetic disturbances related to the recent great earthquakes be detected by satellite magnetometers?, Tectonophysics, 431, 173-195, doi:10.1016/j.tecto.2006.05.038, 2007.

Bortnik, J., Inan, U. S., and Bell, T. F.: Temporal signatures of radiation belt electron precipitation induced by lightning-generated MR whistler waves: 2. Global signatures, J. Geophys. Res., 111, A02205, doi:10.1029/2005JA011398, 2006.

Brun, R., Rademakers, F., Canal, P., et al.: ROOT An Object Orientable Data Analysis Framework User Guide 5.17, 469 pp., July 2007.

Casolino, M., De Simone, N., Di Felice, V., and Picozza, P.: Detection of the high energy component of Jovian electrons in Low Earth Orbit with the PAMELA experiment, Adv. Space Res., 41, 168-173, doi:10.1016/j.asr.2007.07.024, 2008.

Couet, O. and Goossens, M.: HBOOK Statistical Analysis and Histogramming Reference Manual, Information Technology Division, CERN Geneva, Switzerland, 193 pp., 1998.

Cowan, G.: Statistical Data Analysis, Clarendon Press, Oxford, 128 pp., 1998.

Davis, G.: History of the NOAA satellite program, J. Appl. Remote Sens., 1, 012504, doi:10.1117/1.2642347, 2007.

Esposito, G.: Studio della stabilità temporale delle fasce di Van Allen e ricerca di correlazioni di natura geofisica per lo sviluppo di un payload spaziale, Phd thesis, Univ. di Perugia, which can be downloaded at http://ams.pg.infn.it/ esposito/ phd2/thesis2-esposito.pdf, Feb. 2008,

Evans, D. S. and Greer, M. S.: Polar Orbiting Environmental Satellite Space Environment Monitor - 2: Instrument Descriptions and Archive Data Documentation, NOAA Technical Memorandum January, version 1.4, 155 pp., 2004.

Evans, D., Garrett, H., Jun, I., et al.: Long-term observations of the trapped high-energy proton population $(\mathrm{L}<4)$ by the NOAA Po- lar Orbiting Environmental Satellites (POES), Adv. Space Res., 41, 126-1268, doi:10.1016/j.asr.2007.11.028, 2008.

Grigoryan, O. R., Panasyuk, M. I., Petrov, V. L., et al.: Spectral characteristics of electron fluxes at $\mathrm{L}<2$ under the Radiation Belts, Adv. Space Res., 42, 1523-1526, doi:10.1016/j.asr.2007.12.009, 2008.

Horne, R. B., Thorne, R. M., Glauert, S. A., et al.: Electron acceleration in the Van Allen radiation belts by fast magnetosonic waves, Geophys. Res. Lett., 34, L17107, doi:10.1029/2007GL030267, 2007.

Huang, J., Yan, Y., and Liu, Y.: An analysis of solar radio burst events on December 1, 2004, Adv. Space Res., 39, 1439-1444, doi:10.1016/j.asr.2007.03.061,2007.

Inan, U. S., Golkowski, M., Casey, M. K., et al.: Subionospheric VLF observations of transmitter-induced precipitation of inner radiation belt electrons. Geophys. Res. Lett., 34, L02106, doi:10.1029/2006GL028494, 2007a.

Inan, U. S., Piddyachiy, D., Peter, W. B., et al.: DEMETER satellite observations of lightning-induced electron precipitation, Geophys. Res. Lett., 34, L07103, doi:10.1029/2006GL029238, 2007b.

Inan, U. S., Lehtinen, N. G., Moore, R. C., et al.: Massive disturbance of the daytime lower ionosphere by the giant g-ray flare from magnetar SGR 180620, Geophys. Res. Lett., 34, L08103, doi:10.1029/2006GL029145, 2007c.

Krunglanski, M.: UNILIB Reference Manual, Belgisch Instituut Voor Ruimte - Aeronomie, which can be downloaded thogether to the library from http://www.oma.be/NEEDLE/unilib.php/, 2002.

Larkina, V. I., Nalivayko, A. V., Gershenzon, N. I., et al., Observations of VLF emission, related with seismic activity on the Interkosmos-19 satellite, Geomagn. Aeronomy, 23, 684-687, UDC 550.34:550.388.2, 1983.

Lauben, D. S., Inan U. S., and Bell, T. F.: Precipitation of radiation belt electrons induced by obliquely propagating lightninggenerated whistlers, J. Geophys. Res., 106, A12, 29 745-29 770, 2001.

Lekshmi, D. V., Balan, N., Vaidyan, V. K., et al.: Response of the ionosphere to super geomagnetic storms: Observations and modeling, Adv. Space Res., 41, 548-555, doi:10.1016/j.asr.2007.08.029, 2008.

Longden, N., Honary, F., Kavanagh, A. J., and Manninen, J.: The driving mechanisms of particle precipitation during the moderate geomagnetic storm of 7 January 2005, Ann. Geophys., 25, 20532068, 2007, http://www.ann-geophys.net/25/2053/2007/.

Lorentzen, K. R., Blake, J. B., Inan U. S., and Bortnik, J.: Observations of relativistic electron microbursts in association with VLF chorus, J. Geophys. Res., 106, A4, 6017-6027, 2001.

Mandea, M. and Balasis, G.: The SGR 1806-20 magnetar signature on the Earths magnetic field, Geophys. J. Int., 167, 586-591, doi:10.1111/j.1365-246X.2006.03125.x, 2006.

Meredith, N. P., Horne, R. B., Thorne, R. M., et al.: Substorm dependence of plasmaspheric hiss, J. Geophys. Res., 109, A06209, doi:10.1029/2004JA010387, 2004.

Millan, R. M. and Thorne, R. M.: Review of radiation belt relativistic electron losses, J. Atmos. Sol.-Terr. Phys., 69, 362-377, doi:10.1016/j.jastp.2006.06.019, 2007.

Morioka, A., Misawa, H., Miyoshi, Y., et al.: Pitch Angle Distribution of Relativistic Electrons in the Inner Radiation Belt and 
Its Relation to Equatorial Plasma Wave Turbulence Phenomena, Geophys. Res. Lett., 28, 5, 931-934, 2001.

NASA Goddard Space Flight Center, Greenbelt, Maryland, http:// www.cpc.ncep.noaa.gov/products/stratosphere/strat_a_f/ NOAAK.pdf, NOAA-L.pdf, NOAA-M.pdf and NOAA-N.pdf, respectively in 1997, 2000, 2002 and 2004.

Obara, T., Miyoshi, Y., and Morioka, A.: Large enhancement of the outer belt electrons during magnetic storms, Phys. Chem. Earth (C), 24, 1-3, 281-292, 1999.

Press, W. H., Teukolsky, S. A., Vetterling, W. T., and Flannery, B. P.: Numerical Recipes in Fortran 77 The Art of Scientific Computing Second Edition (Volume 1 of Fortran Numerical Recipes), p. 107-110, 2001.

Pulinets, S. A.: Space technologies for short-term earthquake warning, Adv. Space Res., 37, 643-652, doi:10.1016/j.asr.2004.12.074, 2006.

Raulin, J.-P., Pacinia, A. A., Kaufmann, P., et al.: On the detectability of solar X-ray flares using very low frequency sudden phase anomalies, J. Atmos. Sol.-Terr. Phys., 68, 1029-1035, doi:10.1016/j.jastp.2005.11.004, 2006.

Rothkaehl, H., Bucik, R., and Kudela, K.: Ionospheric plasma response to the seismic activity, Phys. Chem. Earth, 31, 473-481, doi:10.1016/j.pce.2006.02.039, 2006.

Rozhnoi, A., Molchanov, O., Solovieva, M., et al.: Possible seismoionosphere perturbations revealed by VLF signals collected on ground and on a satellite, Nat. Hazards Earth Syst. Sci., 7, 617624,2007 , http://www.nat-hazards-earth-syst-sci.net/7/617/2007/.

Schmitz, H., Orr A., and Lemaire, J.: Validation of the UNILIB Fortran library, Bulgarian-Belgian Cooperation Project, 362 pp., 2000.

Sgrigna, V., Carota, L., Conti, L., et al.: Correlations between earthquakes and anomalous particle bursts from SAMPEX/PET satellite observations, J. Atmos. Sol.-Terr. Phys. 67, 1448-1462, doi:10.1016/j.jastp.2005.07.008, 2005.

Sgrigna, V., Buzzi, A., Conti, L., et al.: Seismo-induced effects in the near-earth space: Combined ground and space investigations as a contribution to earthquake prediction, Tectonophysics, 431, 153-171, 2007.
Soraas, F., Aarsnes, K., Lundblad, J. A., and Evans, D. S.: Enhanced Pitch Angle Scattering of Protons at Mid-Latitudes During Geomagnetic Storms, Phys. Chem. Earth (C), 24, 1-3, 281292, 1999.

Soraas, F., Aarsnes, K., Oksavik, K., and Evans, D. S.: Ring current intensity estimated from low-altitude proton observations, J. Geophys. Res., 107, A7, doi:10.1029/2001JA000123, 2002.

Summers, D. and Thorne, R. M.: Relativistic electron pitchangle scattering by electromagnetic ion cyclotron waves during geomagnetic storms, J. Geophys. Res., 108, A4, doi:10.1029/2002JA009489, 2003.

Tverskaya, L. V., Vedenkin, N. N., Ginzburg, E. A., et al.: Dynamics of Radiation Belt Relativistic Electrons in November 2004January 2005, Geomagn. Aeronomy, 46, 2, 146-150, 2006.

Voronov, S. A., Galper, A. M., Koldashov, S. V., et al.: Registration of Sporadic Increase of High Energy Particle Flux near Brazilian Anomaly Region, Proc. of 20th ICRC, 4, 451-452, 1987.

Voronov, S. A., Galper, A. M., Koldashov, S. V., et al.: Observation of high-energy charged particle flux increases in SAA region in 10 September 1985, Cosmic Res., 27, 4, 629-631, 1989.

Walt, M.: Introduction to Geomagnetically Trapped Radiation, Camridge University, Cambridge, 168 pp., 1994.

Walt, M., Voss, H. D., and Pickett, J.: Electron precipitation coincident with ELF/VLF wave bursts, J. Geophys. Res., 107, A8, doi:10.1029/2001JA009100, 2002.

Xuhui, S., Shaoxie, Xu, Yun, Wu, et al.: General proposal for China Seismo-Electromagnetic Satellite Project, Early Warming and Monitoring Earthquake by Using Electromagnetism Detecting Satellite, Int. Workshop Proc., 14, Jakarta, Indonesia, 25-27 July 2007.

Yermolaev, Yu. I., Zelenyi, L. M., Zastenker, G. N., et al.: A Year Later: Solar, Heliospheric, and Magnetospheric Disturbances in November 2004, Geomagn. Aeronomy, 45, 6, 68-719, 2005.

Young, H. D.: Statistical treatment of experimental data, Am. J. Phys., 32, doi.org/10.1119/1.1970295, 1964.

Zong, Q.-G., Zhou, X.-Z., Li, X., et al.: Ultra Low Frequency of energetic particles in the dayside magnetosphere, Geophys. Res. Lett., 34, L12105, doi:10.1029/2007GL029915, 2007. 